\title{
Uushiindaism as a collective poverty alleviation mechanism and social support
}

\author{
Petrus Angula Mbenzi ${ }^{1}$ and Selma Ndeapo Ashikuti \\ University of Namibia
}

\begin{abstract}
There are attempts to break the cycle of poverty among indigent people in communities globally and in Namibia in particular. In Africa, attempts are made to devise various strategies and develop tools to alleviate poverty. There is, thus a need to implement poverty alleviation tools based on the indigenous knowledge system. By employing and promoting the existing tools among the indigenous people, poverty is likely to be alleviated. This paper presents uushiindaism as one of the existing indigenous tools that can be used to lessen poverty among the poor and marginalized people. Using the collectivism theory which advocates for communal, societal, or national interests in various types of political, economic, and educational systems, the study investigates the concept of uushiindaism as practiced by Aawambo. Data was collected through semistructured interviews. The narrative approach is used in the paper to unravel the role, significance and relevance of uushiindaism and to highlight threats to uushiindaism. It is revealed, in this paper, that poverty may be alleviated through sharing of resources, coupled with work related programs and not through the creation of dependency syndrome.

\section{Introduction}

Uushiindaism comes from the Oshiwambo word uushiinda (neighbourliness) which means the quality of being humane to other people showing kindness, love, and compassion. It involves caring for one another, interdependence, brotherhood and fictive kinship by people who live in close proximity. Uushiindaism is thus a social capital which exists among Aawambo and serves as an informal social safety net operating at a community level. Dekker and Uslaner (as cited in Claridge, 2004) define social capital as the value of social networks, bonding similar people and bridging between diverse people, with norms of reciprocity" (p.12). Uushundaism as a social capital, thus, enables local inhabitants to receive health, protection and financial services as neighbours care for one another in a reciprocal manner. Through Uushiindaism, the poor may be lifted out of abject poverty and inequality may be reduced.
\end{abstract}

${ }^{1}$ Petrus A. Mbenzi is an Oshiwambo senior lecturer at the University of Namibia in the Department of Language and Literature Studies. He holds an MA and PHD from the University of Kwazulu-Natal and University of Namibia respectively. He has specialized in Literature and Rhetoric and has authored several school books. His research interests include lexicography, literature, and onomastics and ethnoscience. E-mail: pmbenzi@unam.na

${ }^{2}$ Selma Ndeapo Ashikuti is a lecturer in the Department of Language and Literature Studies, Faculty of Humanities and Social Sciences at the University of Namibia. Her main research interests are in language policy and planning, particularly language-in-education policy, bilingualism and multilingualism and second language learning and teaching. Email: sashikuti@unam.na 
The principles of Uushiindaism find parallels in other African concepts such as Ubuntu, and Ujamaa. Ubuntu "is the principle of caring for each other's wellbeing and a spirit of mutual support while Ujamaa means familhood or brotherhood and involves a settlement where people would live together and work together for the good of all. However, Ujamaa failed because it was a top down approach beset with coercion and threats to submit to villigizasion whereas Ubuntu and Uushiindaism are bottom up bottom-up approaches to poverty alleviation which do not require state sanction to gain currency and rejuvenation. Uushiindaism promotes collectivism as opposed to individualism. It further enhances friendship. This friendship is encapsulated in the Oshiwambo saying: Mushiinda ino mu ningila omulungu oye kuume koye (Do not quarrel with your neighbour because he/she is your friend) (Haapanen, 1955, p.33). In other words, your neighbor extends more assistance to you than your relatives. This system can thus be viewed as a complement to the efforts of the Ministry of Poverty Eradication and Social Welfare, and Churches in alleviating poverty.

Despite the merits of Uushiindaism and its relevance as a tool for alleviating poverty, it has been affected by capitalist tendencies to a certain extent. Nonetheless, the phenomena of Uushiindaism are still present in rural and semi-urban areas.

\section{Statement of the problem}

The Namibian Government has attempted to put mechanisms in place to alleviate poverty. The Government devised strategies for alleviating poverty such as Vision 2030 and national development plans, and the Harambee Prosperity Plan (2016)- a blue print for wealth redistribution and poverty eradication. In addition the NDP3's strategies for social welfare in Namibia are geared towards poverty alleviation. "Among other things, the plan points at increasing the amounts of the welfare grants already implemented, synchronizing the welfare strategies and at introducing special rates for people who cannot afford basic services such as water and sanitation" (Littmarck, 2010, p. 6)

Namibia has also put in place programs aimed at alleviating poverty especially in the rural areas namely the Rural Poverty Reduction Program (RPRP) that became operational between 2005 and 2009. The aim of this program was to reduce poverty in rural areas through provision of clean water, promotion of community based tourism, etc. In addition to Vision 2030 and other programs for alleviating poverty, there are other social benefits which are; maternity leave, sick leave, death benefit and medical benefit as stipulated in the Social Security Act of 1994 as well as the old age pension of $\mathrm{N} \$ 1250$ per month. It is an undeniable fact that social cash transfers have a positive impact on poverty alleviation as they cater for the vulnerable people, but these transfers tend to reduce inequality to a much lesser degree (Levine, Van Der Berge \& Yu 2009).

In 2005, the Basic Income Grant Coalition was established to pilot the basic income grant project in Namibia. The project was spearheaded by the Evangelical Lutheran Church in the Republic of Namibia (ELCRN). The Big Coalition was regarded as a success, but it was considered a controversial method for poverty alleviation in Namibia (Littmarck, 2010). Despite the attempts by the government to reduce poverty, poverty levels continue to rise in Namibia. According to the report of the Namibia Statistics Agency (NSA) (2016) "the Gini coefficient of 0.572 shows that Namibia is one of the world's most unequal countries." (p.6). Furthermore, a recent report by the World Poverty Clock (2018) shows that extreme poverty in Namibia stands at $18 \%$ thus ranking Namibia as a country that is unlikely to reach the United Nations(UN) Sustainable Development Goals (SDGs), one and two which advocate for end to hunger and poverty by 2030.

Notwithstanding the challenges in reducing poverty and inequality, attempts to address the poverty conundrum by the government are commendable. However, these efforts alone cannot 
adequately address poverty in Namibia unless they are complemented by the existing informal safety nets and social capital in rural communities. Shorter (1999) attests to the inclusion of indigenous knowledge in poverty alleviation efforts: "The poor of Africa usually know quite well what has to be done to alleviate their condition" (p. 7). This study thus considers Uushiindaism as an effort that can be used to complement the government's efforts in alleviating poverty.

\section{Literature review and theoretical framework}

There are no specific literature on Uushiindaism, but literature on similar concepts such as ubuntu and related concepts are available. This literature reveals how these concepts have been applied to alleviate poverty in Kenya, Tanzania and South Africa. Metz (2016) defines Ubuntu to be a form of social protection which is "well construed as systematic intervention to help avert poverty ('insurance') or to improve the plight of the poor ('assistance')" (p. 133). Metz further argues that Ubuntu emphasises solidarity, sharing of important goods with other people or in some cases giving away some goods wholly. This implies that the haves are expected to raise the economic status of the have-nots by either responding to their needs partly or by providing them with enough goods depending on the abundance of the resources.

Uushiindaism is one of the existing indigenous tools that can be used to lessen poverty among the poor and marginalized. The collectivism theory which advocates for communal, societal, or national interests in various types of political, economic, and educational systems, is employed in this investigation (Hofstede, 1984). "When working collectively, the less able members of society produce more per unit time than when working alone, so a greater degree of collectivism provides a social safety net" for the low ability members of society (Ahuja, van der Schaar \& Zame, 2016).Yan (2016) emphasises that poverty alleviation can be achieved through collective efforts involving "receiving" and "providing". This means for one to receive, one must provide. It further demonstrates that collectivism advocates for reciprocal obligations and discourages a mere dependency syndrome. In addition to the collective theory, interdependent of construal theory is also applied to investigate the relevance of Uushiindaism among Aawambo. In this theory, one views himself/ herself as a part of a greater social relationship (Cross, Morris \& Gore (2002). This theory is characterized by a "connectedness to others where self-representations are woven with representation of close others; the theory further stresses reciprocal action and mutual assistance among interdependent individuals." (Cross, Morris, \& Gore, 2002). It is thus used to investigate how Uushiindaism interdependence and collectivist cultures could contribute to poverty alleviation.

Manci (2009), who studied poverty alleviation strategies in Umzinklu in South Africa, discovered a principle of, "Ilima/litsema" which is similar to Uushiindaism. Ilima/litsema refers to collective effort. According to AgriNews (2009), "during llima/ litsema, members of different families would move from one family's land to the next, assisting one another, sharing skills and offering technical advice. Litsema was therefore a socio-economic growth strategy that assisted our people towards their own development" (p. 7). This situation finds parallels in Oshiwambo culture in which teamwork for economic activities such as okakungungu or oshitemo is used to perform similar function.

The tenets of litsema fit in with the underlying principles of uushiindaism. The operations of litsema contribute to poverty alleviation and serves as a bulwark against degenerating into extreme poverty. Through litsema families and neighbours maintain a symbiotic relationship in which neighbourly reciprocity plays a dominat role. Manci (2009) underscores the significance of litsema in South Africa: 
This concept speaks of networks and connectedness that increases trust and the ability of people, organisations and institutions to work together and expand their access to a wider and wider range of resources. It thus alludes to the mobilization of appropriate resources for the common good. The adoption of social capital as a key strategic intervention is an acknowledgement by government of the role played by civil society and social networks in building social cohesion. This in turn is essential for achieving national socio economic objectives. These twin objectives find expression in the people's contract to push back the frontiers of poverty (p. 42).

The Government of South Africa appears to have embraced the efforts of the local people to reduce poverty. The principle of Ilima/litsema have been incorporated in the South African government measures of ensuring food security (AgriNews, 2009). Thus the Government of Namibia needs to make use of uushiindaism to fight poverty.

\section{The relations of Uushiindaism to the other related concepts in other indigenous languages of Namibia}

Namibia is a country with few people but many languages. Many of these languages belong to the same subfamily, namely the Bantu family. Etymologically, the Bantu languages have similar lexicostatics which are transparent both semantically and morphologically. Within Bantu languages, one may find linguistic cognates which point to common origin of Bantu. The Bantu do not simply share the same words but they also share some cultural practices. Thus, Uushindaism finds paralles in other Bantu languages of Namibia. In Rukwangali the word musinda has the same meaning as omushiinda in Oshiwambo. The Vakwangali exchange labour and resources such a fish and mahangu. Ploughing may also be carried out in reciprocal manner. Similarly Ovaherero have a concept of Ouraranganda (neigbourliness). Rohde (1997) observes that the Ovaherero of Okombahe show signs of cooperation and bonds because neighbours exchange milk. In Silozi, which is a lingua franca in the Zambezi region, the concept buzwale refers to neighbourliness. In view of this concept, neighbours help one another in various ways including sharing foods and labour.

\section{Methods of research}

Fieldwork of this study was conducted in Oshalongo village in the Oshikoto region. Oshalongo consists of a rural community that lives farther away from urban centers of north central Namibia. It is about 32 kilometre from Omuthiya Town. The aim of conducting the study in this village was to gauge the views of the rural communities on the benefits of Uushiindaism. Further fieldwork was also conducted in Havana in Windhoek to establish whether Uushiindaism has any impact on the life of semi-urban people. Academia, one of the upmarket areas in Windhoek was also included in the study to establish whether the residents of the upmarket areas still maintain the concept of uushaindaism.

Two methods were used to collect information for this study, namely literature review and interviews. Existing studies were consulted to identify methodological lacunae, and also to identify strengths and weaknesses of similar studies conducted elsewhere. The dearth of literature on this subject in Namibia prompted the researchers to consult existing literature from other countries. In addition, interviews were conducted with people from selected areas to establish their views on the effects of Uushiindaism on poverty alleviation and also to determine the impact of the capitalist economy on Uushiindaism. Convenience sampling was used to select the interviewees.

\section{A reflection of poverty alleviation in Oshiwambo proverbs}

Proverbs are said to be powerful communication tools in African societies. They are regarded as the expression of truth and are didactic in nature. In search of an African understanding of the 
issue of poverty, it is important to recognise the contribution of proverbs dealing with poverty as a human condition. Kilimike (2009) opines that:

Proverbs can contribute towards poverty eradication strategies. Hence, a recognition of that contribution in African proverbs (the African perspective) that could more fully illuminate the linguistic imagery that may socialise the poor into transforming rather than accepting their unchangeable situation (the Western perspective) in society (p. 7).

Proverbs enacorage the poor to remain industrious and shun self-pity. Furthermore, proverbs discourage indolence and a dependency syndrome and advocate for hard work. In Africa, people are expected to work hard to earn a living. There are proverbs which emphasise hard work in Oshiwambo:

Omutumba ethete.

(Sitting is like a failure of crop).

Dhomuthigona ihadhi pu molutu.

(The poor is never without energy).

These proverbs demonstrate a positive approach that motivates members of a community to overcome poverty through hard work. In this case, poverty is viewed as a challenge to be overcome and not as a problem (Kilimike, 2006). Similarly, there are proverbs that stress unity in Oshiwambo. The unity and communality inherent in these proverbs entrench Uushiindaism, and by extension the alleviation of poverty. Oshiwambo proverbs such as Omunwe gumwe ihagu itombola na (One finger does not pick a louse); Uuhuku wokwiiyengela ihawu zi (Making marula kernels ready for processing oil alone does not make one produce much oil).

In Aawambo communities, proverbs serve as inspiration forsharing possessions. The following proverbs attest to this situation: Omushiinda gwomunangombe iha ningi omwiinga (The neighbour of the cattleman never becomes poor). When a family does not possess cattle, the neighbour provides it with a herd of cattle to increase the soil fertility and benefit from milk. When one's neighbour, who possesses cows has churned the milk, he invites his neighbours to collect their share. S/he may also send his/her children to deliver sour milk and butter to his/her neighbours. In other words, cow products are shared. Similarly, if one does not have a bull in his herd, he may hire a bull from his neighbour for fertility purposes.

Mutual assistance is also encapsulated in the following adage: Mushiinda ezimo (A neighbor is a family/clansperson) and Mushiinda ino mu ningila omulungu, oye kuume koye (Do not argue with your neighbour, he/she is your friend). Both of these sayings imply that your neighbour is as important as your relatives. One's relative may live far away, thus when s/he is in need, neighbours respond to the needs promptly because of their proximity. Neighbours are encouraged to maintain cordial relationships and to treat one another as close friends. Another proverb which sums up mutual assistance among neighbours is: Yopopepi ya liwa ohula yokokule ya adha okaana ka sa (The one who lives in ones' proximity offers immediate help while the one who lives far from you, will find your child dead). This means that if your child falls sick and needs medical attention, you can seek help from a neighbour, but if you seek help from someone who live some miles away, your child may pass on before s/he arrives. Even in the modern world in which people may communicate with one another through the use of mobile phones, if you require assistance neighbours may respond to your shout for help promptly.

Omushiinda elugo lyopooha (a neighbour is an adjacent cooking area). This is linked to a polygamous system which existed among Aawambo in ancient times. In this system each wife 
owned a separate cooking area (elugo), and these areas were adjacent to each other. This is rooted in the notion that when one wife did not have enough food, she relied on another wife for support.

\section{Uushiindaism and communal work}

Communal work or teamwork is one of the elements of uushiindaism. Neighbours in the Aawambo communities assist one another in subsistence farming. During the cultivation season when one sees that another person's land has not been ploughed, he/she asks his/her entire family to assist with the planting. When weeding starts, a group of neighbours, especially women may organise themselves to go and till the land of their neighbour. The leader of okakungungu informs the kraal owner that she would bring okakungungu to his field. S/he then invites his/her friends and neighbours to help weed the field. This may be done by giving a piece of okapolo (makalani stick) called oshikuni. Whoever receives oshikuni passes it on to his/her friends until it reaches the last woman in the proximity of the kraal owner. On the set day, women invade the field of the kraal owner and weeds incessantly until sunset. The kraal owner prepares food and drinks for the workers.

Similarly, when a woman sees that her neighbours's field has been invaded by weed, she organises etamu. Tirronen (1986) defines etamu as 'a meeting for hoeing up the weed in a cornfield from early morning until evening without a break." In addition, Amakali (1993) describes etamu as teamwork for weeding in which women work invade the cornfield of a neighbour without informing him/her. It is organised by one woman who uses the oshikuni process described before. The difference between okakungungu and etamu is that in okakungungu, the labourers may pause for a break for refreshment and resume their works after refreshment.

Communal work is carried out by neighbours reciprocally during harvesting as well. This may be called ondjabi. They may inform the owner of the land that they would like bring okakukula to his/her field Loeb (1962) describes okakukula as follows:

If a kraal owner has a larger crop than his wives can thresh, he holds a threshing feast very much like the weeding feast. He asks a foreman from a neighbouring kraal to bring women workers with their stamping sticks on a certain day. Their payment will be a feast of ox or goat, meat, beer and porridge (p. 151).

Although Loeb stresses that a foreman is asked to bring women to the threshing floor, there are occasions when a group arrives at the threshing floor uninvited. They begin threshing mahangu while singing songs to while away tiredness. They shout to the kraal owner: Owa tila! Owa tila! (You are afraid! You are afraid!). This is called okwiiyakela molupale (sneaking into the threshing floor). The kraal owner responds: Inandi tila (I am not afraid). Consequently the kraal owner and his wife begin preparing food and beer for the workers. Khombo (2011) observes that "people can work together in community groups in order for them to be more productive, for example, they farm, construct roads, fish or fell trees together, while they are singing traditional songs as part of morale boosting (p. 134). Khombo notes (2011) that "in Africa, the traditional heritage in many regions reflects the cultural norms of working together, developing a sense of co-operation, and helping one another in times of adversity and prosperity. Supporting the family is a symbol of solidarity and the interests of the family are always a priority" (p. 122).

Although threshing has been women's work, in the early late seventies and early eighties, men began to take part in this agricultural activity. They organise themselves in groups and use thick sticks to thresh mahangu. However, their activity is never called okakukula, but is referred to as ondjabi. 
Another interviewee relates that: Women organise themselves to pound mahangu together. This activity is called oshilangeka. Tirronen (1986) defines oshilangeka as pounding early in the morning. In this activity girls take turns in pounding mahangu at different neighbours' houses as a form of social interaction. A girl would spend a night at the neigbours' homestead and they would wake up very early in the morning to pound mahangu together. This activity is completed before dawn. In a related activity the girl would go to the neighbour's homestead and they pound mahangu together when the moon is in full. This activity is called oshaamwedhi.

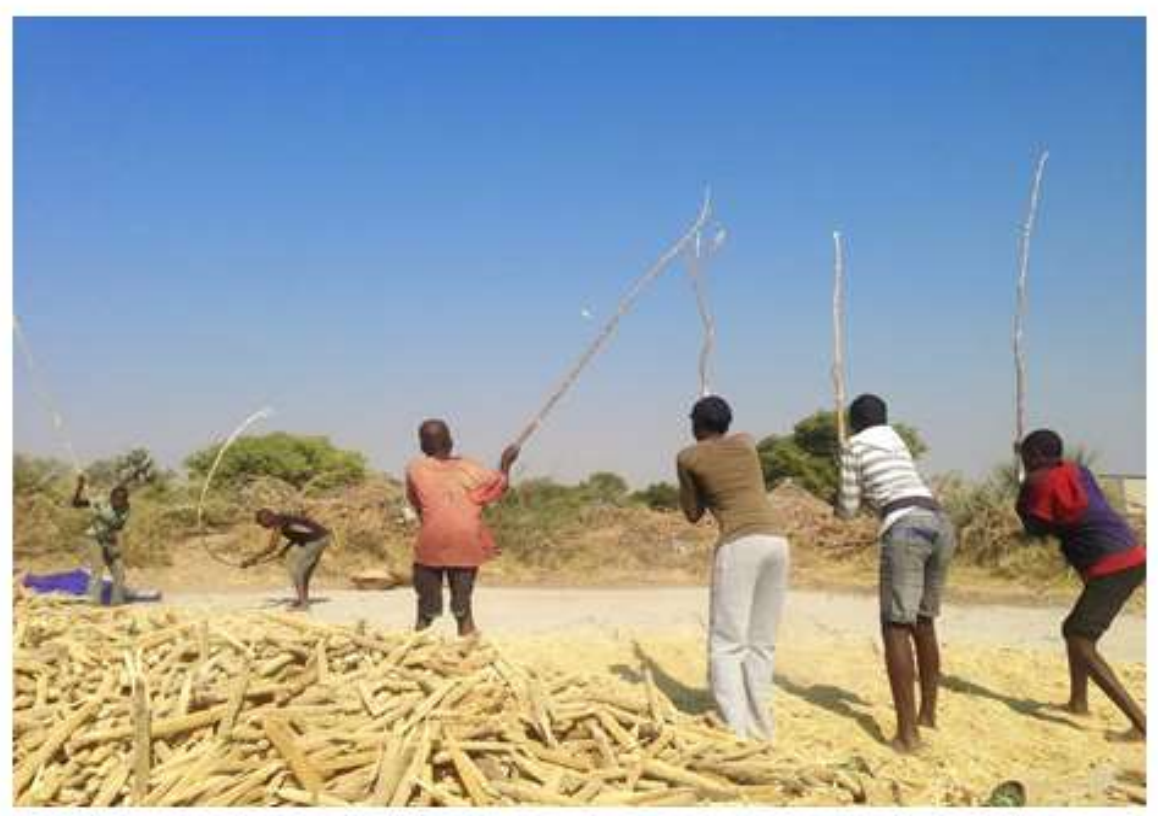

Uushiindaism during threshing

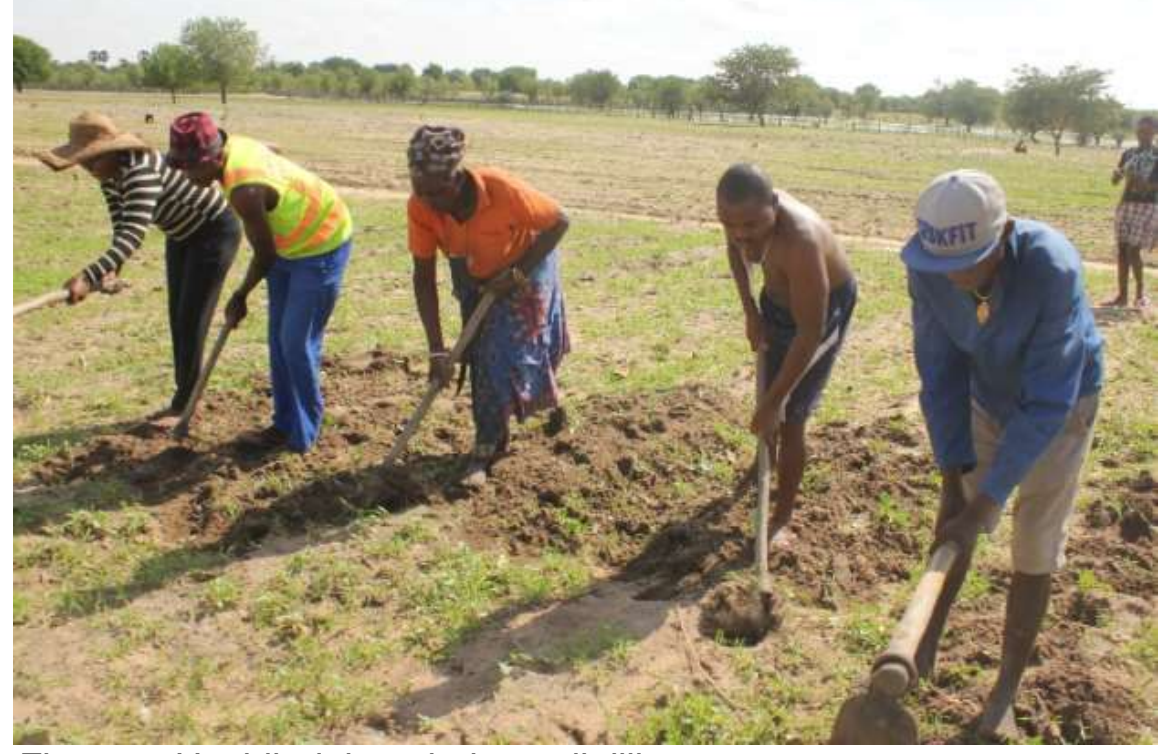

Figure 2. Uushiindaism during soil tilling
Figure 1. 


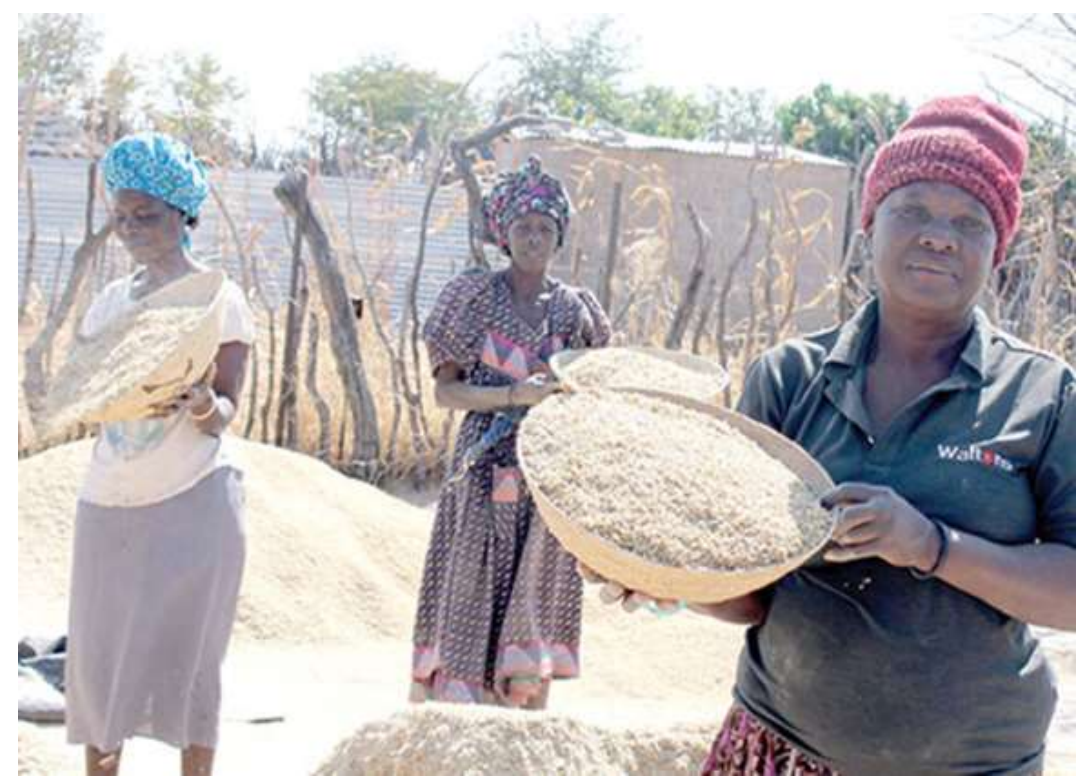

Figure 3. Uushiindaism during winnowing

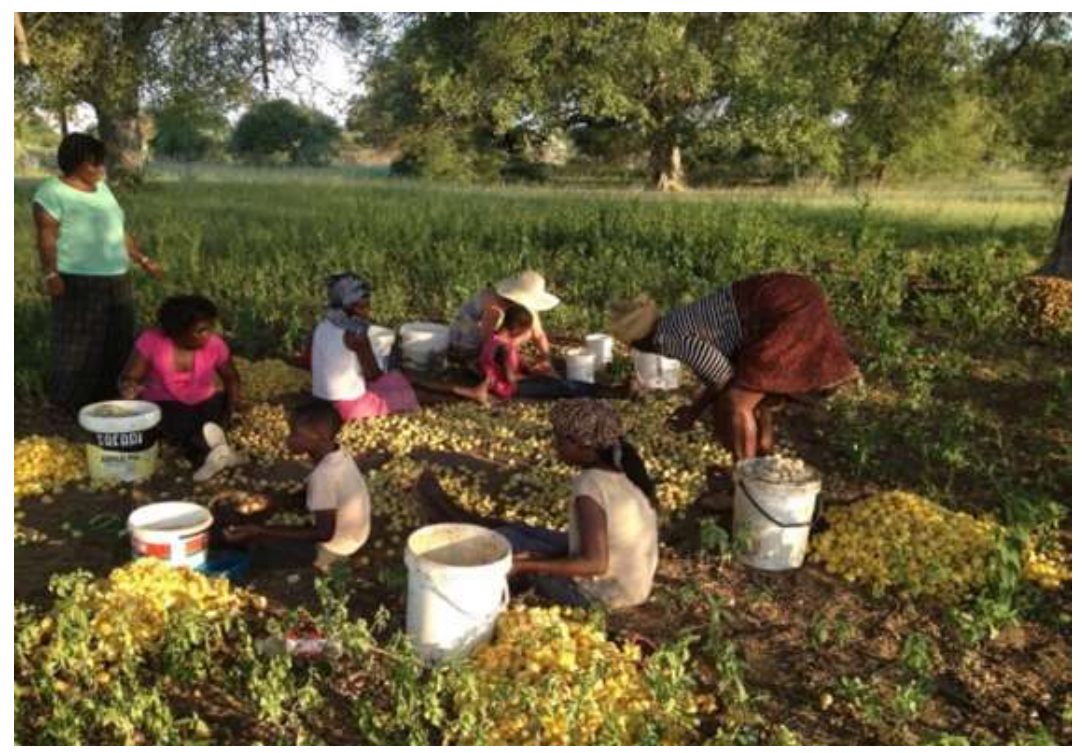

Figure 4. Uushiindaism during the extracting of marula juice

Apart from communal threshing, animal herding is practiced communally. This means that young boys in the community tend animals together as neighbours. As a means of social interaction, communal animal herding allows young boys to play various traditional games together. Another form of communal animal herding is the herding of animals by turn-taking. This means young boys would take turns in herding animals belonging to the neighbours. This allows young boys to do other house chores and to rest from this tedious work. In the ancient times, unity and close cooperation were powerful and as result neighbours herded animals together.

\section{Uushiindaism and ceremonies}

Ceremonies in Oshiwambo culture requires collective effort. There are two important ceremonies in which uushandaism plays a significant role, namely wedding ceremonies and funeral ceremonies. Traditionally, when a neighbour passes on, the Aawambo announce the death through wailing, ululation and beating of drums depending on the nature of death or status of the 
deceased. A person struck to death by lightning or a royal person's demise is announced by ululation. That said, the ululation for announcing death is marked by breaks at regular intervals. The death of other commoners is announced by wailing. Upon hearing the wailing or ululation, neighbours of the deceased rush to a homestead where the shouting comes from to share the grief with the bereaved family. It is a common practice for Aawambo to accompany one another to ceremonies, both of sadness and joy.

In addition, the neighbours bring along drinks and foods to assist the bereaved family during the mourning period. They also raise funds to assist with the buying of food and burial necessities. Manci (2009) found similar terms among the residents of Umzimkulu in South Africa. The community of Umzumkhulu has many systems in place to curb the scourge of poverty. They used both traditional and modern methods in fighting poverty. On the social and economic level, the society still engages in the traditional customs of 'izipheko' that is providing food gifts at ceremonies. They also assist physically through labour at these ceremonies (p. 371). Aawambo also help the bereaved family physically with cooking, collecting wood and water during the mourning period. Some neighbours go to the extent of providing shelter, cooking utensils and chairs for the mourners. At present, the provision of such assistance is to some extent influenced by capitalist tendencies as some neighbours would expect the bereaved family to pay for such service. During wedding ceremonies, neighbours also help one another. The assistance extended to the family commences when the parents of the groom or bride invite their neighbours. The parents may be given mahangu or sorghum to process them for food or drinks during the ceremony.

On the day of omaimbilo (choral music?) or prior to that day, the neighbours may bring chickens, goats, oxen and, as is modern practice, cases of beers and cool drinks. They may also bring foods such as potatoes, macaroni, rice, odjove (marula oil) etc. They may come to live in the homestead of the bride or bridegroom and assist the parents with chores such as skinning oxen, cooking, brewing beer and so on.

\section{Uushiindaism and education}

In Oshiwambo culture, child rearing and upbringing has been a joint responsibility of all parents in a particular community. Children were disciplined and taken care of by all parents. If a child was found breaking any rule in the community such as picking unripe fruits or polluting water, $\mathrm{s} /$ he was given a hiding by any parent. This is rooted in the famous African proverb, "it takes a village to raise a child".

A gainfully employed neighbour would also buy the neighbours' children school uniform and pay school fees. There are cases of children whose tuition fees have been settled by their neighbours from secondary to tertiary institutions. In addition, urban dwellers may give shelter to students of their neighbours back in the village and contribute to the payment of school fees. Their rural neighbours are expected to reciprocate by providing them with flour, beans, etc. which are not readily available in urban areas. The evidence of such cases is revealed in the excerpt below:

Neighbours can lift one out of abject poverty (Aashiinda otayi ku kutha puutokele). Look, I have relatives in Windhoek. Some of them are well off and live in affluent areas, but when my daughter completed Grade 12 none of them was willing to assist me. A neighbour of mine decided to cover the transport fees of my daughter to and from UNAM over four years until she graduated with Bachelor of Education. Currently she is a teacher in the north and she supports me financially. Had it not been for my neighbour my daughter could have dropped out of UNAM. 
Capacity building is enhanced through skills transfer, e.g. a woman without skill in marula oil processing may be trained by a neighbour. Another example of skills transfer comes in the form of teaching others how to brew mahangu beer and to produce ombike (afro-gin). During these processes, the person lacking the skill invites the neighbour to train them. This is not a once-off task; rather it is a continuous process that involves rigorous demonstrations until the trainee masters the skill. In the absence of a father from a household mainly due to the contract labour system, boys were taught skills such as thatching and ploughing by the men in the vicinity.

Successful farming in Namibia seems to be dependent on cross-fertilization of ideas and skills tranfers among the farmers who live in close proximity. According to the Forum for Future and Konrad-Adenauer Foundation (2017):

All residents should display friendly neighbourliness to each other, assisting and advising each other so that the house remains strong and stable and everyone feels supported and cared for. For example, we have established and experienced commercial farmers. We also have upcoming and inexperienced commercial farmers. There should be a spirit of friendly neighbourliness between them. When they support one another, the success of one farmer becomes the success of his/her neighbour (p. 23).

This quotation proves that neighbourliness is recognised as useful mechanism in the social uplifment of communities in Namibia. Although the quotation makes particular reference to farming sector, the concept can be applied cross-sectionally. Furthermore, capacity building may be enhanced through mentorship programs thus promoting synergy effects.

\section{Uushiindaism as conduit for community care services}

Through uushiindaism, sharing is the golden rule, hence the alleviation of poverty. It thus has the same core principles as Ujamaa "the basic feeling of recognition and respect for one another; communal ownership of the major means of production as a way of avoiding class division in society and; the obligation to work" (Sansa, 2010, p. 3).

Neighbours share food, clothing, implements, services etc. The economic status of vulnerable people is elevated. Communal work is promoted to enhance food production. Communality creates a conducive environment for vibrant and prosperous communities (Mosha, 2002). In another example, a young girl can pound mahangu into flour for an elderly, a widowed person or any neighbour in need of help. Similarly, a young boy can tend animals for neighbours who are in need of the service. These include the widowed, elderly and those without young boys.

During the contract labour system, albeit horrible as it was, contract labourers shared their possessions with their neighbours. They shared soap, oil, sugar and clothes, cosmetics. The oombwiti (cosmopolitans) also invited the children of the neighbours to their homestead to enjoy sweets with their children. During the festive season, particularly on Christmas day, people who did not have access to modern food and drinks such as rice, bread, canned drinks and sweets received such items from their neighbours. A wealthy person in the community invited all his/her neighbours to celebrate with him/her at his/her homestead.

When harvesting fish, the owner of the fish pond invites neighbours to get their share. The same rule applies to the sharing of fruits. Neighbours help one another in planting, tilling, harvesting and threshing of the agricultural products. Hiring of draught animals, bulls, cocks, ploughing equipment, etc. to increase productivity is also a common practice. Neighbours assist one another in times of difficulties and in times of joy. Sharing of lighters by collecting fire coals from neighbours or lighting cow dung at the neighbours is a common practice. Commenting on Ujamaa in Tanzania, Ergas (1980) explains that: 
It is true that poor farmers in rural areas assist each other during the peaks of the agricultural season, particularly the women who do the weeding and harvesting of the foodstuffs. Peasants also help each other for the periodic rebuilding of their thatch-roofed mud huts. And solidarity is still strong on important social occasions, like burials and weddings, and in emergencies such as serious disease and fires (p. 381).

Equally Uushiindaism promotes interdependence among Aawambo, e.g. when hunger strikes a certain family, the wife puts either a sand or cow dung in a basket and carries it to her neighbour. Sand or cow dung in the basket symbolise hunger. The neighbour who receives such a basket put in mahangu in response. When a neighbour slaughters a cow or goat, s/he makes sure that every neighbour receives a share, hence the saying Muushinda esipa lyothingo (A neighbour is a neck bone). This Oshiwambo adage make references to sharing of food. When an Omuwambo slaughters an animal, the neck of an animal especially an ox is shared among neighbours. It does not mean only the neck, but other parts of a slaughtered animal may be shared. The owner of the slaughtered animal ensures that his/her neighbours are provided with their share of the meat. The meaning of this saying, Muushinda esipa lyothingo, is however not confined to sharing of meat alone. The neck bone being the connector of the head and the rest of the body (of a human, in this case), it is significantly related to the importance of a neighbour. When you feed yourself through mouth, you literally need the neck to transport the food/nutrients to the rest of the body, therefore, you cannot feed yourself adequately without the support of the neighbour because s/he is as important as the neck bone.

Similarly, when a neighbour has churned milk, s/he shares butter and milk with his/her neighbours. The same rule applies to the sharing of fruits. This means that when one does not share fruits or milk with others, they may be regarded as a bad neighbour (omushiinda gwoshigonga). According to Uushiindaism, a neighbor is expected to exhibit the behaviour of generosity and caring for others who are in need.

People living in the same community share labour. For example, if a parent is absent for a few days from his homestead due to hospitalisation or for some other reasons, s/he would leave the children in the care of one of his/her neighbours. Such a neighbour would ensure that the children have food and a generally well taken care of. S/he would cook for them and bring them food at their house or he would ask them to have lunch and supper with his/her family. Younger children could also be accommodated in homestead of a neighbour until their parents' have returned. Tevdten (2008) narrates the support extended to a neighbour in Oshakati who needed medical care after she was beaten by her husband:

When I first met Felicidade she said she had tried to get out of the marriage for a long time, but that she needed the little money he gave her and didn't know how to leave him. A few months later neighbours found Felicidade badly beaten. Then her aashiinda, neighbours took action: They took her to the hospital, and took care of her children while she was there. When Felicidade came out of the hospital they took her and the children into another house, guarded them there until the story had calmed down, and supported her economically to get restarted with her okapana business. (p. 150).

Such sympatheic attitude is commonly exhibited among neighbours. The clear evidence of this attitude is reported by two Havana residents of Windhoek:

One cannot live without neighbours. Your neighhours act as a police force. I fell sick a year back and was hospitalised in Katutura hospital. My relatives are in the north-central Namibia 
and could not come to visit me due to financial problems. My neighbours visited me frequently and brought me foods and drinks. They took turns in paying me a visit. After I was discharged from the hospital, they paid me a visit at my house. Another positive aspect is that we share a lot of things. If I do not have enough fire woods or salt, I go to one of my neigbours for help.

Another participant makes similar observation:

Neighbourliness promotes unity and peaceful co-existence. When I fell sick a year ago I did not have money. My neighbour got a taxi for me and was taken to Katutura Hospital. He paid for taxi fares and cared for my children while was in hospital. My children never went hungry in my absence. My neighbours cooked for them everyday. My youngest daughter was hosted by my neighbour until I was discharged.

\section{Threats to uushindaism}

Despite the merit and the positive effects Uushiindaism has on the livelihood of the rural and semirural communities, it appears to be under threat at present. Acculturation seems to have contributed to the decline of Uushiindaism. Thus the tenets of uushiindaism have been adversely affected resulting in the ostracism of the poor and the vunerable groups.

Aawambo who live in urban centers, particularly those residing in the affluent areas have partly abandoned their cultural practices and are therefore immersed in western culture. In the upmarket areas uushiindaism is virtually non-existent. The better-off who live in informal selltements have grealtly minimised their interaction with the shanty-dwellers. Tevdten (2008), writing on social relations of Aawambo in Oshakati reports that urbanisation has given rise to the emergence of cosmopolitanism.

This demonstrates that poverty is likely to skyrocket as the better- off elite are generally unwilling to share their posssessions with the neighbours. This situation is not confined to urban areas only, but in rural communities. There are some educated elites who do not like to interact with the poor. Trevdten (2008) explains that:

Even rural areas some traditional patterrns are changing. Like in the past: neigbours used to cook and call up other neighbours to eat and celebrate, but now this is becoming rare. Now the rich do not like to associate with the poor, and the poor envy the rich. People nowadays are even jealous of each other, especially if you have someone supporting you from urban centers (p. 122).

One of the interviweees attributes "the blatant breach of neighbourly reprocity." (Rohde, 1997, p. $168)$ to high crime rate in urban areas:

The haves fear of the criminals and consider the shanties as the breeding ground for the criminals. They do not want to exchange visits with shanty dwellers because they fear that they will steal from them. They have electrical fences to protecet themselves against thieves who are believed to be hiding in the shanties.

This implies that increase in crime rate has an impact on uushiindaism, particularly in urban areas where burglaries and armed robberies are reported frequently. Mistrust, suspicion reign in these areas.

Furthermore, the desire for money economy leads to the breakdown in uushiindaism. Hiring cutlery, crockery and chairs, and table without charge is on the decline, because catering services have been commercialised. At present neighbours hire their items for a fee. Such tendency 
affects the spirit of reciprocity to a greater extent. Similarly the less educated people are unwilling to exchange their labour for free. Economic activities such as planting, weeding, and harvesting have been commercialised. The views of the residents of the middle-income areas in Windhoek indicate that uushiindaism in urban areas makes little or no dent in promoting co-existence and reciprocal assiatance. Out of ten people interviewed only one interviewee indicated that neighbourly reciprocity and interaction exist between them and their neighbours:

Neighbourliness here in our suburb is very poor. We know one another with our neighbours, but our interaction is only limited to greetings. We never visit one another. Week and weeks by without seeing each other. I can recognize their faces but I do not know their names.

The definition of the word, neigbour here in town is different from the definition of the word, neighour in rural areas. Interdependence among town dwellers is very minimal. We live a complete isolation here. If I want to socialize, I go to Katutura where my relatives are. If experience any problem I cannot call the so-called neigbours. Mbuno owo nee uushiinda woshigonga mbuka tu li wuwo (This is what unreliable neighbourliness is all about). There is poor or no communication among people who live in close proximity.

The problem here in upmarket residential area is that we hail from different cultural groups. It is difficult to interact with someone who does not know your culture. Kandi na aashiinda ondi na ashiinda edhina (I do not have real neigbours, I have neighbours in name only). We say good morning to one another but we do not visit one another. Our interaction is limited to exchange of greetings only, but we need to establish neighbourliness so that we can prevent crimes.

Although Uushindasism is reported to be virtually non-existent in the middle and upper income areas, high crime rate in these areas of Windhoek appears to have compelled the residents to resort to Uushindaism to a lesser extent through the creation of Neighbourhood Watch Association whose aim is to reduce crime by organizing the people who live in an area to watch each other's property and inform the police about possible criminals.

\section{Conclusion}

Uushindaism is still present among Aawambo today. Aawambo still maintain this practice despite their exposure to western culture. This practice performs various functions to alleviate poverty thereby complementing the government's efforts in its quest to eradicate poverty in Namibia. Families in favourable circumstances assist their neighbouring families that are in need, by providing them with food items, clothes and other basic needs. However, such assistance is often accompanied by reciprocal obligation.

Uushindaism is very powerful in rural setting and informal settlements as informants from both rural areas such as Oshalongo and Havana testified while informats from the middle and upper income area of Windhoek such as Academia uushindasim is virtually non-existent. Furthermore, uushindaism appears to be under threat, because in rural setting some people are reluctant to share their properties for free. The sharing of furniture, crockery and cutlery is beginning to decline as the 'affluent' are bent on hiring their properties for a fee. Nonetheless uushindaism still yields positive results and is a bulwark against abject poverty in several rural communities.

There is, thus, a need to rely on the existing structures within Namibian communities to address poverty and to encourage the communities already engaged in communal work and sharing of wealth to heighten the practice of sharing. It is in sharp contrast to uumatakomuningilwa (dependency syndrome) and promotes reciprocal obligations as inherent in Oshiwambo proverbs. 


\section{References}

Claridge, T. (2004). Social capital and natural resource management: An important role for social capital? Unpublished Thesis, University of Queensland, Brisbane, Australia.

Cross, S. E., Morris, M. L., \& Gore, J. S. (2002). Thinking about oneself and others: The emotion, and motivation. Psychological Review, 98(2), 224-247.

Ergas, Z. (1980). Why did the Ujamaa village policy fail? - Towards a Global Analysis. The Journal of Modern African Studies, 18 (3), 387-410.

Forum for future and Konrad-Adenauer foundation. (2017). Towards our all inclusive Namibian house. Windhoek: Konrad-Adenauer-Stiftung.

Hofstede, G. (1984). Culture's consequences: International differences in work-related values. Newbury Park, CA: Sage.

Ilima/Letsema ensuring food security. (2009, January). AgriNews: Official newsletter of the Department of Agricuture, p. 7.

Kilimike, L. P. (2006). An African perspective on poverty proverbs in the book of proverbs: Analysis for transformational possibilities. (Doctoral dissertation). University of Pretoria.

Levine, S., Van Der Berge, S. \& Yu, D. (2009). Measuring the impact of social cash transfers on poverty and inequality in Namibia. University of Stellenebosch.

Littmarck, S. (2010). Basic Income Grant Towards poverty alleviation in Namibia: A discourse analysis of conceptions of poverty and poverty alleviation within the BIG Coalition. (Master's thesis). Linkooings Universitet.

Manci, P.E. (2009). The response of African religion to poverty, with specific reference to the Umzimkhulu municipality. (Unpublished Doctoral Dissertation). Unisa, Pretoria, South Africa.

McMahon A, McMahon R. 2005. Language classification by numbers. Oxford, UK: Oxford University Press.

Metz, T. (2016). Recent philosophical approaches to social protection: from capability to Ubuntu. Saga Journal, 16 (2), 132-150.

Mosha, R. S. (2002). The heartbeat of indigenous Africa: A study of the Chagga educational system. London: Routledge.

Mukhungulu, M. J., Kimuthi, V. A. \& K'Odhiambo, A. K. (2017). African philosophy of education: Analysis of the neglected ideals of Nyerere's Ujamaa. Journal of Education and practice, 8(15), 178-184.

Namibia Statistics Agency. 2016. Namibia Household Income and Expenditure Survey 2015/16.

Republic of South Africa Government Gazette (1996, February 2). Government Welfare Paper on Welfare No. 16943. Pretoria, South Africa, 18.

Rohde, K. F. (1997). Nature, cattle thieves and various other midnight robbers. University of Edinburgh.

Sansa, G (2010). The impact of institutional reforms on poverty and inequality in Tanzania (Unpublished Doctoral dissertation). University of Bath, Bath, South England.

Yan, K. (2015). Poverty alleviation in China: A theoretical and empirical study. Beijing: Springer. Republic of South Africa Government Gazette (1996, February 2). Government Welfare Paper on Welfare No. 16943. Pretoria, South Africa, 18.

McMahon A, McMahon R. 2005. Language classification by numbers. Oxford, UK: Oxford University Press 